${ }^{1}$ Department of Restorative Dentistry, Dental School, Shahid Beheshti University of Medical Sciences, Tehran, Iran.

${ }^{2}$ Department of Restorative Dentistry, Dental School, Shahid Beheshti University of Medical Sciences, Tehran, Iran.

${ }^{3}$ Dental Clinic of AmirAlam Hospital, Tehran University of Medical Science, Tehran, Iran.

${ }^{4}$ Dental School, Hamedan University of Medical Sciences, Hamedan, Iran.
Corresponding author: Mahsa Mohammadi Email:mmahsa604@gmail.com

Received: July 17, 2020

Accepted: January 16, 2021

\section{Influence of laser deproteinization of acid-etched dentin on marginal microleakage of class $\mathbf{V}$ composite restoration}

\author{
Shahin Kasraei ${ }^{1}$ (D), Sogol NejadKarimi ${ }^{2}$ (D), Mona \\ Malek $^{3}$ (D), Mahsa Mohammadi $4, \star \star$
}

Aim: Recent reports indicate that deproteinization of acid-etched dentin surface can extend penetration depth of adhesive agents. The main goal of the present research was to investigate the deproteinization effect of Nd:YAG and diode 940 lasers on acid-etched dentin and microleakage grade in class $\mathrm{V}$ composite restorations. Methods: 36 extracted human premolar teeth were selected to make standard buccal and lingual class $V$ cavities. These samples were randomly split into three sub-groups: 1.Control group, in which composite was applied for restoration after etch and bonding process without deproteinization; 2.Nd:YAG laser group, in which the teeth were deproteinized with Nd:YAG laser after etching and painting internal surfaces of cavities with Van Geison stain and then composite restorations applied just as control group; 3.Diode laser group, in which the process was similar to Nd:YAG laser group, but instead, diode 940 laser was irradiated. The teeth were bisected into two equal longitudinal buccal and lingual halves. Marginal microleakage of samples was scored by using a stereomicroscope. KruskalWallis, Mann-Whitney $U$ and Fisher's statistical tests were employed for analysis of the obtained data. Results: A significant reduction in marginal microleakage was observed for both groups treated with laser ( $\mathrm{Nd}$ :YAG and diode 940)compared to control $(p=0.001 \& p=0.047)$. There was no significant difference in marginal microleakage between Nd:YAG laser and diode 940groups ( $P=0.333$ ). Conclusion: $N d: Y A G$ and diode 940 laser deproteinization of acid-etched dentin decreased the marginal microleakage of in-vitro class $\vee$ resin composite restorations.

Key words: Acid etching, dental. Dentin-bonding agents. Dental leakage. Lasers. 


\section{Introduction}

There have been many studies to improve the quality of composite restorations bonding and decrease microleakage until now. Many techniques such as oblique layering technique, using lining materials, different curing modes and pre-polymerized composite inserts have been tried on adherend surface to reduce this microleakage, however, there exists no method to eliminate the microleakage of gingival margin completely yet ${ }^{1-4}$.

One of the recommended method for adherent surface to reduce the marginal microleakage complication is to eliminate or decrease the collagen network in acid-etched dentin and composite interface by the use of different materials such as enzymes, proteolytic agents ${ }^{3-6}$ or lasers ${ }^{2,5,7}$.

Considering the recent progress in laser technology, laser irradiation is used to improve bonding quality in dental restorations by chemical modification of the substrate materials ${ }^{8,9}$. The collagen network can be ablated selectively by using special features of lasers. Additionally collagen network has the potential to be painted by special dyes which can differentiate the collagen network and enhance the effectiveness of collagen removal from acid-etched dentin surface without any effect on mineralized tissue $2,3,8,9$

Deproteinization of dentin surface creates an adequate mineral substrate for adhesion to resin, hence, decreases marginal microleakage in composite restorations significantly ${ }^{2,7}$. The decreased marginal microleakage causes more durability and success for restoration and decreases post operative sensitivity ${ }^{2,10,11}$. In this regard, few studies recommended Nd:YAG laser as a deproteinizing agent for acid-etched dentin 2,12 .

Notably, diode lasers as well, have a wavelength in about 800 to 1064 nm and hemo-

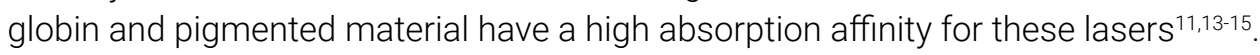

In the previous studies it has shown that employing lasers after etching the dentin by acid would improve the strength of bonding, reduce the microleakage and enhance the marginal adaption between the tooth and the restorative materials ${ }^{12,16-19}$. In the present study, the effect of simultaneous utilization of two lasers, including Nd:YAG and Diode 940, in addition to employing Adper Single Bond 2 and LED curing either using dyes to absorb the laser beams are considered as the main novelty. In this regard, the influence of deproteinization of acid-etched dentin by $\mathrm{Nd}$ :YAG and diode 940 laser on the marginal microleakage of in vitro class $\vee$ composite restorations are assessed and consequently the effectiveness of the two lasers in reducing microleakage is compared.

\section{Methods}

Thirty six extracted human premolar teeth, without restorations, caries, anomalies, observable defect or crack, were scrubbed and stored in 10\% buffered Formalin. One week prior to the experiments, the teeth were placed in distilled water at $20-22^{\circ} \mathrm{C}$ 
room temperature. The teeth were randomly split into three sub-groups, each with twelve specimens.

Conventional bevel class $V$ cavities $(3 \times 2 \times 2 \mathrm{~mm}$ in height, width, and depth, respectively) were provided in the buccal and lingual surfaces of each tooth 1-mm above the cementoenamel junction (CEJ) area. Therefore, there attained three groups, each group contains 12 teeth (24 samples). The classical class $V$ cavities, in which $1 \mathrm{~mm}$ was above the CEJ in enamel, $1 \mathrm{~mm}$ in cementum or dentin under the CEJ.

The cavities were prepared by one practitioner with grain diamond burs (835/010, Diamant Gmbh, D\&Z, Berlin, Germany, $1 \mathrm{~mm}$-diameter), under water cooling, which were replaced after each 9cavities prepared. A bevel with 0.5 to $0.7 \mathrm{~mm}$ width was produced on enamel, only the incisal margins, with angel of 45 degree. Specimens with exposed pulp were not considered in the current study. The classifications of the groups tested in the present study are as follows:

Control group: Based on manufacturer's instructions, the teeth were etched with a 35\% phosphoric acid etchant (3M Oral Care, St. Paul, MN, USA) for 15 seconds which was used in the dentin and enamel starting with the enamel margins. The samples completely rinsed off phosphoric acid gel with distilled water. The surface of the dentin was dried with an absorbing tissue paper butlet to retain a slight moist surface with no visible excess of water on the tooth surface (blot drying). Immediately after blotting, 2 adhesive consecutive coats (Adper Single Bond2, 3M Oral Care, St. Paul,MN,USA) employed in acid-etched dentin for 15 seconds by applying gentle agitation utilizing a fully saturated applicator and carefully dried for five seconds with air spray to eliminate solvents.

Applied bonding agent was light cured (Woodpecker LED, Guilin , China) for 10 seconds at $1000 \mathrm{~mW} / \mathrm{cm}^{2}$ light intensity (to ensure accurate performance, radiometer was applied for assessment of the light-curing unit). Finally, cavities were filled with composite (3M ESPE, Filtek Z250, St. Paul, MN,USA) in three incremental oblique layers respectively cervical layer at first, occlusal layer second, and the last layer was complete composite restoration. To ensure complete polymerization, each layer light cured for 40 seconds separately.

Nd:YAG laser group: The same strategy established for control group, except that after etching, Nd:YAG laser irradiated with Van Geison stain for removal of the exposed collagen network. Van Geison stain was provided by blending $1 \%$ aqueous fuchsine solution $(9 \mathrm{ml}$ ) with $50 \mathrm{ml}$ distilled water and $50 \mathrm{ml}$ saturated aqueous picric acid solution. A fine layer of Van Geison stain was used on the internal surface of the cavities with a micro-brush applicator. The dye was carefully brushed into the dentin for 5 seconds in a fine motion. Then the teeth were sprayed with air and rinsed with water and treated with Nd:YAG laser (Fotona, Fidelis3 Plus, Ljubljana, Slovenia); the pulse width of $300 \mu$ second (SP Mode) with $1 \mathrm{~mm}$ distance from the surface; with $1.5 \mathrm{~W}$ output power and a frequency of $15 \mathrm{~Hz}$ for 10 seconds. The diameter of fiber optic was $300 \mu \mathrm{m}$ and fiber tip adjusted perpendicular to the cavity surface by hand at an approximate distance of $1 \mathrm{~mm}$ in sweeping movement with the speed of $2 \mathrm{~mm} / \mathrm{sec}$. Since the hand piece is applied and controlled by the operator, the same approach is used to have similar output. Cavities restored with composite and cured the same as control group. 
Diode 940 laser group: The same procedure performed as for $\mathrm{Nd}$ :YAG laser group except that diode 940 nm (Epic 10, BIOLASE, Inc.4 Cromwell Irvine, CA ,USA) was irradiated. The specifications of the used laser beam were as follows: $940 \mathrm{~nm}$ wavelength; fiber optic diameter of $300 \mu \mathrm{m}$ without initiation, mode cp1, pulse length $100 \mu$ second, an average output power of $1 \mathrm{~W}$, duty cycle was 33\% and pulse interval was $200 \mu$ second. The distance of lasers tip was about $1 \mathrm{~mm}$ vertically from cavity surface and all the surfaces lased for 10 seconds by the speed of $2 \mathrm{~mm} / \mathrm{sec}$. Finally, the procedure of restoration was terminated with fine grit diamond burs (Chatsworth, CA, USA) and polishing disks (Soft-Lex, 3M ESPE, St. Paul, USA) were used to polish the samples similar to the other groups.

The samples were put in distilled water at $24^{\circ} \mathrm{C}$ for $24 \mathrm{hr}$ after restoration procedure. The specimens were subjected to thermocycling (Nemo Co., Mashad, Iran) for 3000 cycles at $5^{\circ} \mathrm{C}( \pm 2)$ and $55^{\circ} \mathrm{C}( \pm 2)$ with $30 \mathrm{sec}$ and $20 \mathrm{sec}$ dwell and transfer times, respectively. Afterwards, distilled water at $24^{\circ} \mathrm{C}$ was used for storing the restored teeth for six months. Subsequently, the apex of teeth sealed with wax and the surfaces of the samples, except the restoration surfaces and $1 \mathrm{~mm}$ around the restorations' margins, were coated with nail varnish (Fig1).

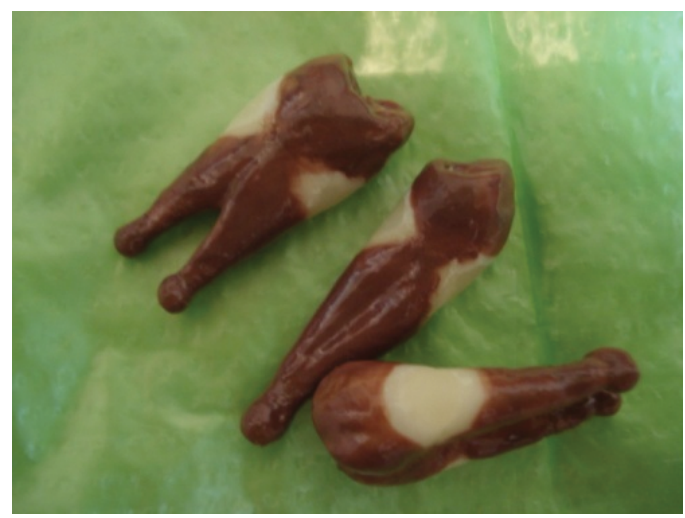

Figure 1. The teeth were coated with nail varnish up to $1 \mathrm{~mm}$ of restoration border.

Afterwards, the samples were put in $1 \%$ fuchsin basic solution at $20-22^{\circ} \mathrm{C}$ for $72 \mathrm{hr}$, then rinsed and dried. A diamond disk (Diamant Gmbh, D\&Z, Berlin, Germany) was applied in a handpiece in low-speed and water spraying condition to divide the samples into two pieces, in order to make them appropriate for observation under stereomicroscope.

The assessment of the microleakage was performed under a stereomicroscope (SZ40, Olympus, Tokyo, Japan) at $\times 40$ by two blind observers. In cases of difference values, the higher one is selected as the final value. The dye penetration of two halves were examined separately and evaluated at interface of tooth-restoration and scored as follows:

Grade 0: Without dye penetration.

Grade 1: Dye penetration up to the half of the lateral cavity wall, either incisal or the cervical, of the tooth-restoration interface. 
Grade 2: Dye penetration to the wall of whole lateral cavity without involving the axial wall.

Grade 3: Dye penetration in direction of the axial wall (Fig 2).

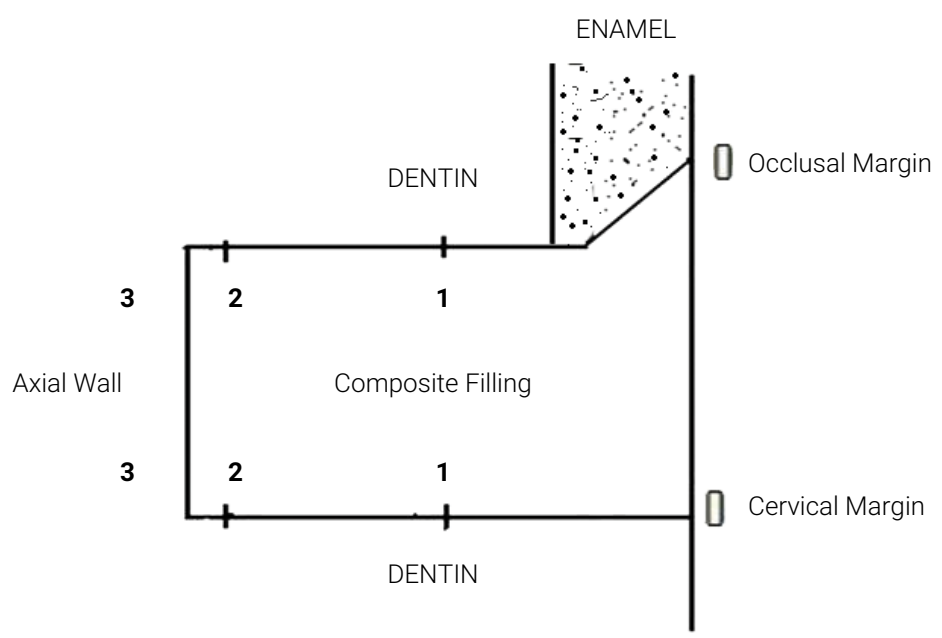

Figure 2. Schematic figure of dye penetration in specimens.

Kruskal-Wallis, Mann-Whitney $U$ and Fisher's statistical tests were applied to analyze the data at a significant level of $\mathrm{P}<0.05$.

\section{Results}

Microleakage scores at dentin and enamel margins of restoration are represented in table 1. The Kruskal-Wallis tests showed significant differences between cervical (Dentin) margins $(p=0.001)$ but there were no significant differences between groups in occlusal (Enamel) margins $(p=0.549)$. The microleakage score of occlusal margins of restorations were less than cervical margins $(p=0.001)$

Table1. Comparison of the microleakage scores achieved in margins of class $\mathrm{V}$ composite restorations in studied groups

\begin{tabular}{|c|c|c|c|c|c|c|c|c|c|c|}
\hline \multirow{2}{*}{$\begin{array}{l}\text { Scores } \\
\text { Groups }\end{array}$} & \multicolumn{5}{|c|}{ Microleakage score in dentin margins } & \multicolumn{5}{|c|}{ Microleakage score in enamel margins } \\
\hline & 0 & 1 & 2 & 3 & *P-Value & 0 & 1 & 2 & 3 & *P-Value \\
\hline Control & 0 & $\begin{array}{c}10 \\
(41.66 \%)\end{array}$ & $\begin{array}{c}9 \\
(37.5 \%)\end{array}$ & $\begin{array}{c}5 \\
(20.83 \%)\end{array}$ & & $\begin{array}{c}19 \\
(79.16 \%)\end{array}$ & $\begin{array}{c}5 \\
(20.83 \%)\end{array}$ & 0 & 0 & \\
\hline $\mathrm{Nd}: Y A G$ & $\begin{array}{c}8 \\
(33.3 \%)\end{array}$ & $\begin{array}{c}13 \\
(54.16 \%)\end{array}$ & $\begin{array}{c}3 \\
(12.5 \%)\end{array}$ & $\begin{array}{c}0 \\
(0 \%)\end{array}$ & 0.001 & $\begin{array}{c}21 \\
(87.5 \%)\end{array}$ & $\begin{array}{c}3 \\
(12.5 \%)\end{array}$ & 0 & 0 & 0.549 \\
\hline Diode 940 & $\begin{array}{c}5 \\
(20.8 \%)\end{array}$ & $\begin{array}{c}11 \\
(45.83 \%)\end{array}$ & $\begin{array}{c}7 \\
(29.16 \%)\end{array}$ & $\begin{array}{c}1 \\
(4.16 \%)\end{array}$ & & $\begin{array}{c}18 \\
(75 \%)\end{array}$ & $\begin{array}{c}6 \\
(25 \%)\end{array}$ & 0 & 0 & \\
\hline
\end{tabular}

*Kruskal Wallis test at significant level of $p<0.05$ 
Pairwise comparison between groups in dentin margins of restorations by complementary Mann-Whitney $U$ tests showed significant difference between dentin margins of restorations in control versus Nd:YAG groups $(p=0.001)$ and between control versus diode laser groups $(p=0.047)$; although there were no significant difference in microleakage of restorations between two laser groups $(p=0.333)$.

\section{Discussion}

Microleakage is among the most important challenges in restorative dentistry ${ }^{20,21}$. Uncompleted diffusion of adhesive resin component via the outermost demineralized dentin will lead to non-resin infiltrated collagen networks low hydrolysis, the process that weakens the resin-collagen network over time ${ }^{2}$. Decreasing or removing the collagen network in resin-dentin interface can improve the strength of bond and reduce marginal microleakage ${ }^{2,22-24}$

The aim of the current research was to assess the effect of deproteinization of acid-etched dentin by Nd:YAG and diode 940nm laser on microleakage of in vitro class $\checkmark$ composite restoration. The results revealed that deproteinization of dentin surface by irradiation of each Nd:YAG and diode 940 lasers significantly decrease microleakage of cervical margins in class $V$ restorations.

Previous studies showed that applying Nd:YAG and diode lasers before etching in class $V$ composite restorations have no impact on decreasing of dentin marginal microleakage of composite restoration ${ }^{25,26}$.It was reported that laser irradiation of cavity surface before etching with acid increases subsurface cracks and micro cracks on laser-irradiated surfaces ${ }^{27}$. These micro cracks increase microleakage in dentin-restoration interface ${ }^{26,27}$. However, other studies revealed that using lasers after etching the dentin by acid can increase the bonding strength, decrease microleakage and improve marginal adaptation between restoration and tooth ${ }^{12,16-19}$. They stated that etching the dentin with phosphoric acid decrease the stability of the collagen fibers and removal of the exposed collagen matrix from the etched dentin surface increase dentin wettability and bond strength of composite restorations 2,19,28.

The collagen network has potential to be stained by special dyes (e.g. Van Geison stain); etched dentin with acid, stain the collagen network, and expose the dentin to laser by modifying favorable parameters, the collagen network will be removed selectively and deproteinized the dentin without effecting the inorganic substance. The elimination of collagen from the etched dentin leads to reduction in organic content, improve the energy of the surface and change the dentin hydrophilic features; consequently, the adhesive monomers penetration into the dentin will be enhanced ${ }^{3}$. Dayem ${ }^{12}$ showed that the Nd:YAG laser can remove the collagen network from acid etched dentin more thoroughly than can $10 \% \mathrm{NaOCl}$.

Incomplete diffusion of resin monomers into etched dentin, and hydrolysis of collagen fibrils that have not been covered with resin, lead to increasing microleakage and reducing bond strength over time. Improving the penetration of resin monomer into demineralized dentin creates more reliable hybrid layer that increase bond quality, so marginal microleakage of class $V$ composite restorations will be reduce by this deproteinization method ${ }^{2,28}$. 
It seems that $\mathrm{Nd}$ :YAG laser irradiation via fusion and re-crystallization of dentin apatite crystals, removing of smear layer and elimination of collagen fibril of the smear layer, leads to formation of stronger and more durable bond ${ }^{20,29}$. Their results agreed with a significant reduction in cervical microleakage in the present study. However, we did not observe any significant differences between the two types of lasers in reducing cervical microleakage.

Despite the results of the present study, Kawaguchi et al. reported that the use of lasers after etching has no effect on restorations marginal microleakage ${ }^{30}$. It should be noted that the lasers irradiated parameters used in our study were completely different from these researches. Obeidi et al. showed decrease in marginal microleakage of composite depends on parameters of irradiated laser beam ${ }^{31}$. Additionally we used dyes to absorb the laser beams. These differences may be impressive to explain the different results of current study. The use of Van Gieson dye increases the absorption of $\mathrm{Nd}$ : YAG laser energy by stained collagen fibers, so better removal of organic matter and etched dentin collagen occurs, without causing the dentin to crack or change the hydroxyapatite crystals by laser beam energy. Some researchers have suggested that the negative effect of $\mathrm{Nd}$ : YAG laser beam radiation on the bond strength before applied adhesive agent is due to absorbed energy of the laser to mineral materials and changing the chemical structure of the dentin and causing cracks in it ${ }^{30}$. It should be noted that the results of the present study could not be obtained by reducing the $\mathrm{Nd}$ :YAG laser energy fluency without collagen staining, because by performing stained collagen, the ratio of laser absorption coefficient in organic to mineral materials has changed. By increasing this ratio, the energy required to degrade and eliminate collagen fibrils is obtained without structural changing the dentin minerals.

There was no significant difference in microleakage of dentinal margins between the two lasers tested $(p=0.102)$. These two lasers had similar wavelengths in infrared, both absorbed by melanin and other stains and both have almost the same effect on collagen fibers colored with stains. Laser absorption by stained collagen fibers cause protein distortion and finally the deproteinization effect of them are similar to each other approximately ${ }^{32}$. More evaluation of the differences between these two lasers, are suggested by using different parameters such as irradiation time and pulse energy, using other etch and rinse bonding systems and laser employing without coloring, according to laser absorption in protein materials. Future studies comparing this method with other techniques might further characterize the advantages and disadvantages of this procedure. Fourier transform infrared spectrometry and near-infrared spectrometry for better evaluations was recommended $10,11,15$.

Dentin in gingival margin has a wet surface refers to its nature. Since, it is critical point for bonding mechanism of current dental bonding agents and can increase the microleakage Therefore, like most previous studies we have observed that the microleakage on dentin margins of restorations is more than enamel margins ${ }^{20,33,34}$. In order to enhance the survival of composite restoration, it is necessary to ensure a durable bonding of resin composite to enamel and dentin margins ${ }^{35}$.

Under the conditions set for the current study, it can be concluded that Nd:YAG and diode 940 lasers deproteinization of acid-etched dentin can lead to less marginal microleakage of in-vitro class $V$ composite restorations. 


\section{Conflict of Interests}

All of the named authors have been involved in the work leading to the publication of the paper and have read the manuscript before its submission for publication. The authors declare that they have no conflict of interest.

\section{Acknowledgments}

The authors thank the Dental Research Center and the Vice Chancellor of Research of Hamadan University of Medical Sciences for supporting this study.

The present article is in-vitro and does not require institutional ethics committee approval in our country, Iran.

\section{References}

1. Gupta J, Saraswathi V, Ballal V, Acharya S, Gupta S. Comparative evaluation of microleakage in Class $\checkmark$ cavities using various glass ionomer cements: An in vitro study. J Interdiscip Dent. 2012;2(3):164. doi:10.4103/2229-5194.113245.

2. Dayem RN. Assessment of the penetration depth of dental adhesives through deproteinized acid-etched dentin using neodymium: Yttrium-aluminum-garnet laser and sodium hypochlorite. Lasers Med Sci. 2010;25(1):17-24. doi:10.1007/s10103-008-0589-4.

3. Dayem RN, Tameesh M. A new concept in hybridization: Bromelain enzyme for deproteinizing dentin before application of adhesive system. Contemp Clin Dent. 2013;4(4):421. doi:10.4103/0976-237x.123015.

4. Scheffel DLS, Hebling J, Scheffel RH, Agee KA, Cadenaro M, Turco G, et al. Stabilization of dentin matrix after cross-linking treatments, in vitro. Dent Mater. 2014;30(2):227-233. doi:10.1016/j.dental.2013.11.007.

5. Inai N, Kanemura N, Tagami J, Watanabe LG, Marshall SJ, Marshall GW. Adhesion between collagen depleted dentin and dentin adhesives. Am J Dent. 1998;11(3):123-7.

6. Chauhan K, Basavanna RS, Shivanna V. Effect of bromelain enzyme for dentin deproteinization on bond strength of adhesive system. J Conserv Dent. 2015;18(5):360-3. doi:10.4103/0972-0707.164029.

7. Barcellos DC, Holleben P, Fonseca BM, Sabino BC, Gonçalves SEP. The effect of self-etching adhesive system associated with different energy densities of Nd:YAG laser on microtensile bond strength to dentin. Lasers Dent Sci. 2018;2(3):157-62. doi:10.1007/s41547-018-0033-4.

8. Ural Ç, Külünk T, Külünk Ş, Kurt M. The effect of laser treatment on bonding between zirconia ceramic surface and resin cement. Acta Odontol Scand. 2010;68(6):354-9. doi:10.3109/00016357.2010.514720.

9. Casucci A, Mazzitelli C, Monticelli F, Toledano M, Osorio R, Osorio E, et al. Morphological analysis of three zirconium oxide ceramics: Effect of surface treatments. Dent Mater. 2010;26(8):751-60. doi:10.1016/j.dental.2010.03.020.

10. Maenosono RM., Bim Júnior O, Duarte MA, Palma-Dibb RG, Wang L, Ishikiriama SK. Diode laser irradiation increases microtensile bond strength of dentin. Braz Oral Res. 2015;29(1):1-5. doi:10.1590/1807-3107bor-2015.vol29.0004

11. Rezaei-Soufi L, Kasraei S, Fekrazad R, Vahdatinia F, Moghimbeigi A, Haddad, et al. Evaluation of Diode laser $(940 \mathrm{~nm})$ irradiation effect on microleakage in class $V$ composite restoration before and after adhesive application. J Dent Mater Tech. 2018;7(1):11-8. 
12. Dayem RN. A novel method for removing the collagen network from acid-etched dentin by neodymium:yttrium-aluminum-garnet laser. Lasers Med Sci. 2009;24(1):93-9. doi:10.1007/s10103-007-0528-9.

13. Savadi Oskoee S, Alizadeh Oskoee P, Jafari Navimipour E, Ahmad Ajami A, Pournaghi Azar F, Rikhtegaran S, et al. Comparison of the effect of Nd:YAG and diode lasers and photodynamic therapy on microleakage of Class $\mathrm{V}$ composite resin restorations. J Dent Res Dent Clin Dent Prospects. 2013;7(2):74-80. doi:10.5681/joddd.2013.013.

14. Kasraei S, Yarmohamadi E, Jahromi PR, Akbarzadeh M. Effect of 940nm Diode laser irradiation on microtensile bond strength of an etch and rinse adhesive (single bond 2) to dentin. J Dent. 2019;20(1):30. doi:10.30476/DENTJODS.2019.44560.

15. Golbari N, Kasraei S, Afrasiabi A, Mostajir E, Mojahedi SM. Effect of diode laser (810 nm) irradiation on marginal microleakage of multi-mode adhesive resins in class $\mathrm{V}$ composite restorations. J Lasers Med Sci. 2019;10(4):275-82. doi:10.15171/jlms.2019.45.

16. Lisboa DS, dos Santos SV, Griza S, Rodrigues JL, Faria-e-Silva AL. Dentin deproteinization effect on bond strength of self-adhesive resin cements. Braz Oral Res. 2013;27(1):73-5. doi:10.1590/S1806-83242013000100013.

17. Shafiei F, Memarpour M, Fekrazad R. Sealing of Silorane-based Composite in Laser-prepared Primary Teeth: Effect of Acid Etching. Pediatr Dent. 2014;36(5):378-83.

18. Celik EU, Kucukyilmaz E, Savas S. Effect of different surface pre-treatment methods on the microleakage of two different self-adhesive composites in Class V cavities. Eur J Paediatr Dent. 2015;16(1):33-8.

19. Lee BS, Lin PY, Chen MH, Hsieh TT, Lin CP, Lai JY, et al. Tensile bond strength of Er,Cr:YSGG laser-irradiated human dentin and analysis of dentin-resin interface. Dent Mater. 2007;23(5):570-8. doi:10.1016/j.dental.2006.03.016.

20. Kasraei S, Yarmohammadi E, Farhadian M, Malek M. Effect of proteolytic agents on microleakage of etch and rinse adhesive systems. Braz J Oral Sci. 2017:e17048-e17048. doi:10.20396/bjos.v16i1.8651051.

21. Baghalian A, Nakhjavani YB, Hooshmand T, Motahhary P, Bahramian H. Microleakage of Er:YAG laser and dental bur prepared cavities in primary teeth restored with different adhesive restorative materials. Lasers Med Sci. 2013;28(6):1453-60. doi:10.1007/s10103-012-1222-0.

22. Baseggio W, Consolmagno EC, de Carvalho FLN, Ueda JK, Schmitt VL, Formighieri LA, et al. Effect of deproteinization and tubular occlusion on microtensile bond strength and marginal microleakage of resin composite restorations. J Appl Oral Sci. 2009;17(5):462-6. doi:10.1590/S1678-77572009000500021.

23. Shetty S, Mithra B, Sureshchandra B. Dentine deproteinization and microleakage around gingival third resin restorations. J Conserv Dent. 2008;11(1):11. doi:10.4103/0972-0707.43412.

24. Maeda FA, Fukushima KA, Tedesco TK, Aranha ACC, Raggio DP, Miranda Junior VG, et al. Effect of erosive challenge and Nd:YAG laser irradiation on bond strength of adhesive systems to dentin. Int J Adhes Adhes. 2016;64:60-4. doi:10.1016/j.ijadhadh.2015.09.008.

25. Armengol V, Jean A, Enkel B, Assoumou M, Hamel H. Microleakage of class $V$ composite restorations following Er:YAG and Nd:YAP laser irradiation compared to acid-etch: an in vitro study. Lasers Med Sci. 2002;17(2):93-100. doi:10.1007/s101030200016.

26. Arslan S, Yazici AR, Görücü J, Pala k, Antonson DE, Antonson SA, et al. Comparison of the effects of Er,Cr:YSGG laser and different cavity disinfection agents onmicroleakage of current adhesives. Lasers Med Sci. 2012;27(4):805-11. doi:10.1007/s10103-011-0980-4.

27. Moretto SG, Azambuja N, Arana-Chavez VE, Reis AF, Giannini M, Eduardo CP, et al. Effects of ultramorphological changes on adhesion to lased dentin-Scanning electron microscopy and transmission electron microscopy analysis. Microsc Res Tech. 2011;74(8):720-6. doi:10.1002/jemt.20949. 
28. Dayem RN. A novel method for removing the collagen network from acid-etched dentin by neodymium:yttrium-aluminum-garnet laser. Lasers Med Sci. 2009;24(1):93-9. doi:10.1007/s10103-007-0528-9.

29. Gan J, Liu S, Zhou L, Wang Y, Guo J, Huang C. Effect of Nd:YAG laser irradiation pretreatment on the long-term bond strength of etch-and-rinse adhesive to dentin. Oper Dent. 2017;42(1):62-72. doi:10.2341/15-268-L.

30. Kawaguchi FA, Eduardo CP, Matos AB. Nd:YAG Laser Influence on Microleakage of Class V Composite Restoration. J Clin Laser Med Surg. 2003;21(4):227-9. doi:10.1089/104454703768247800.

31. Obeidi A, Ghasemi A, Azima A, Ansari G. Effects of pulsed Nd:YAG laser on microleakage of composite restorations in class V cavities. Int Congr Ser. 2003;1248(C):175-9. doi:10.1016/S0531-5131(03)00053-0.

32. Huang Z, Lui H, Chen XK, Alajlan A, McLean DI, Zeng H. Raman spectroscopy of in vivo cutaneous melanin. J Biomed Opt. 2004;9(6):1198. doi:10.1117/1.1805553.

33. Ahmadi R, Ramazani N, Daryaeian M, Nabavi S. In vitro comparison of microleakage of nanofilled and flowable composites in restoring Class $\mathrm{V}$ cavities in primary molars. Zahedan J Res Med Sci. 2013;15(1):47-51.

34. Kimyai S, Ajami AA, Chaharom MEE, Oskoee JS. Comparison of microleakage of three adhesive systems in class $\mathrm{V}$ composite restorations prepared with Er,Cr:YSGG laser. Photomed Laser Surg. 2010;28(4):505-10. doi:10.1089/pho.2009.2562.

35. Maior JRS, Figueira MAS, Netto ABAB, Souza FB, Silva CHV, Tredwin CJ. The importance of dentin collagen fibrils on the marginal sealing of adhesive restorations. Oper Dent. 2007;32(3):261-5. doi:10.2341/06-75 